2011-01-01

\title{
Using an Adaptive Scenarios Approach to Establish Strategies for Tomorrow's Workplace
}

\author{
Ruth Saurin \\ Technological University Dublin, ruth.saurin@tudublin.ie \\ John Radcliffe \\ Henley Business School, john.ratcliffe@henley.com
}

Follow this and additional works at: https://arrow.tudublin.ie/futuresacart

Part of the Sociology Commons

\section{Recommended Citation}

Saurin, R., Radcliffe, J. (2011) : Using an adaptive scenarios approach to establish strategies for tomorrow's workplace. Foresight, Vol. 13 Iss: 4, pp.46-63. 2011. doi:10.1108/14636681111153968

This Article is brought to you for free and open access by the Futures Academy at ARROW@TU Dublin. It has been accepted for inclusion in Articles by an authorized administrator of ARROW@TU Dublin. For more information, please contact arrow.admin@tudublin.ie, aisling.coyne@tudublin.ie,gerard.connolly@tudublin.ie.

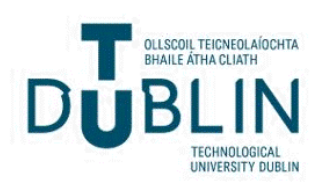




\section{Using an adaptive scenarios approach to establish strategies for tomorrow's workplace.}

\section{Introduction}

Nowadays, most organisations will experience some kind of discontinuous change new markets, new locations, new competitors, new work patterns, and new technologies. As businesses respond to these pressures, a knock-on effect is the changing demand on work environments. Consequently, the workplace is in a state of transition which is having a profound impact upon the way in which organisations plan, design, finance, occupy, use and manage the workplace. Since change remains the one constant in the workplace, all that is certain is the workplace of the future will be very different from that of today. For now, all those involved in workplace provision need to understand the interrelated issues, forces, and factors that determine the future shape and performance of the workplace. Therefore, the critical issue is how to anticipate and manage change.

In response to this challenge, it is argued that a more imaginative, innovative, yet systematic approach towards the study of the future is required of those involved in the provision of work environments. This paper suggests it can be provided by the adoption of the prospective through scenarios process and its associated techniques. The central contention of this paper, however, is that it is important to have a methodological process that is reflexive and flexible to achieve fluid interactions that add rigour and energy to the overall process of a built environment project. In part one, therefore, the context for applying futures thinking to the field of workplace provision is provided. Part two presents an outline of how the prospective through scenarios process was employed in a study entitled "Workplace of the Future". More importantly, it describes how the methodological framework evolved during the course of the study. And finally in part three, a critique of the methodology is proffered, which highlights the advantages of a value-driven adaptive process, but also its limitations.

\section{PART ONE}

\section{The changing workplace}

Workplaces have undergone dramatic changes during the last number of decades as society shifts towards a post-industrial knowledge era. Historically, employees had a permanent place of work, with a fixed desk or office. Technological developments were in their infancy. The use of cellular offices emphasised hierarchies and individualism, and represented corporate success (Harris, 2006). However, recent research has identified powerful driving forces of change that are having a profound impact on the use of current workplace, such as( Ratcliffe et al, 2009):

- the emerging trend of knowledge work;

- the changing demand for flexible employment contracts;

- the impetus for delivering action on sustainability accelerating worldwide;

- the growth of leaner organisations;

- the increased number of mobile and distributed workers; and, 
- the exponential rate of technological development.

As such, today's workplace is very different from those of the recent past. With the rise of knowledge work and the average desk occupied for only 45 per cent of office hours (Nathan and Doyle, 2002), Harrison et al (2004) identifies new environments of work, such as collaborative workspaces; multiple workplaces; distributed workplaces; and, hybrid workplaces (physical and virtual). The development of these work settings suggest that space is now allocated according to work activities (Laing et al, 1998); workplaces consist of both individual and group work settings to optimise productivity (Smith, 2003); and, work environments now go beyond the office building to incorporate various work environments which include public and client spaces supported by technology platforms.

If change remains the one constant, then workplaces will probably be very different in years to come. The future workplace, therefore, will, more than ever, need to be actively 'sustained' to stay effective for the organisation. Yet, all too often,' Workplace' studies are about design, and not about the ways in which the workplace is actively used, supported and sustained over time.

\section{Limitations of existing workplace planning and strategy approaches}

Workplace change and innovation has become critical to the future of organisations in a dynamic, economy-driven and knowledge-based society. Anticipating and managing future change is a vital dimension underpinning successful transition - to new work styles, patterns and locations. However, traditional workplace planning methods are rather limited in their ability to fulfil this task.

Over the years, the traditional approach of research in the real estate domain has been primarily empiricist and retrospective. Decision makers have a propensity to analyse time series data and perform more elaborate calculations. However, these approaches can overlook many deeper questions, especially about the future (Ratcliffe, 2008). Similarly, Vischer (2010) contends workplace strategies are reactive and retrospective; rather than innovative and embracing of change, while the workplace is seen by managers as a "necessary evil" rather than a "strategic asset" (Price \& Akhlagi, 1999). According to Duffy (2000), designers and facilities managers are failing to provide innovative new solutions that support emerging work processes which suggests users and organisations remain in outdated facilities and workspaces.

Despite this, a movement known as alternative officing (AO) emerged in the 1990s initially to reduce costs, but over the years its focus has shifted towards managing uncertainty in organisations and using space as a tool to improve corporate performance and leverage organisational change (Becker, 1999; Becker and Sims, 2000; Steelcase, 2000). The underlying premise is that new workspace concepts universal activity settings, non-territorial offices, telecommuting, collaborative environments and virtual work environments (Becker, ibid) - are developed based on the interaction between people, space and working culture (Nathan and Doyle, 2002). Methods such as bench marking, time utilisation surveys, pre and post occupancy evaluation are just some of the tools that measure the feasibility of these strategies, yet they fail to consider the wider economic, social, environmental and cultural context within which an organisation operates (Harrison et al, 2004). According to 
Harris (2006:51) "macro-level changes ${ }^{1}$ bring about wholesale change to workplace needs". Therefore, all those involved in the provision of physical and virtual workplaces need to understand more about the forces that are driving change in the workplace and their impact, not only on individuals, but also on the organisation.

In recent literature, workplaces are being recognised as complex adaptive systems (Haynes and Price, 2004), which are comprised of individual agents that adapt as they interact with each other and their environment. Therefore workplaces have the ability to evolve, adapt to and accommodate spontaneous order. Under the remit of complexity theory, planning approaches enable decision makers to consider the bigger picture rather than detail, and focus on a range of possibilities for the future (Kelly et $a l, 2005)$. In reality, however, there is a tendency to continue to separate the physical elements from the social, economic, technological and organisational aspects of the workplace as decision-makers retain a deep-rooted belief that the physical work environment is a neutral factor in improving productivity (Smith, 2003). Looking at these components individually can often lead to an oversight of significant connections and interdependencies between them resulting in ineffective workplace policies and practices.

In an environment of growing complexity, heightened uncertainty and rapid change, various shortcomings can be further highlighted in prevailing workplace planning and strategy practices, which include:

- Ineffective mechanisms to deal with complexity and future change in the workplace ${ }^{2}$;

- Short-term view when assessing future workplace requirements (Gibson, 2000:10);

- All too often, there is limited collaboration between stakeholders, such as users, facilities managers, architects, and corporate decision makers reinforcing the silo effect in organisations (Duffy and Tanis, 1993; McGregor, 1994; Duffy, 2000);

- Failure to provide visionary and innovative solutions (McGregor, 2000);

Today, many decision makers in workplace provision still plan and invest based on forecasts of past trends and current conditions. Arguably, the emergence of influential drivers of change is making it increasingly difficult to continue on this "business as usual" trajectory. To address this issue, it is suggested here that a fresh, more innovative and creative approach towards the future is required.

\section{The futures approach}

The futures approach is about future proofing present policy, ensuring that decisions made today are robust enough to withstand the uncertainties of tomorrow. It is based on the notion that the future can be explored and its events anticipated, and as it is not predetermined, human actions can influence its course (Ratcliffe 2002a). As such, the

\footnotetext{
${ }^{1}$ Globalisation, economic pressures, rapid technological development, an ageing population, changing political agenda.

${ }^{2}$ A series of strategic interviews were conducted by the authors in February and March 2010 as part of a larger PhD study. The views reflect a diverse range of stakeholders responsible for the development of workplace planning and strategy.
} 
purpose of futures studies is to "discover or invent, examine and evaluate, and propose possible, probable and preferable futures" (Bell, 2003).

At a theoretical level, futures studies does not possess the boundaries of traditional disciplines, but rather it is trans-disciplinary in nature (Inayatullah, 1998) and constitutes a relatively new evolving knowledge base (Slaughter, 1996). Consequently, futures studies is not defined by a hegemonic paradigm; instead a range of epistemological and theoretical perspectives can be used when undertaking futures studies, such as positivist, constructivist and critical research dimensions (Inayatullah, 1998). It is argued that this position, its openness towards self-definition, gives it an advantage over traditional disciplines that have become institutionalised and domesticated (ibid).

As a result, futures studies employ a wide range of methods, such as forecasting, simulation, planning, trend extrapolation and scenarios (Poli, 2010), all of which facilitate the exploration of the future in a systematic and rigorous manner, particularly in times of increasing levels of uncertainty, accelerating change and growing complexity. An underlying assumption of futures studies is that the future is fundamentally plural and open (Dator,1996; Schultz, 2003; Poli, 2010), thus rendering attempts at prediction futile. As such, futures studies encourages people to look beyond the familiar and to search for a variety of alternatives. Key to this is the development of scenarios.

\section{Scenarios}

According to Schwartz (1991:4), scenarios are instruments for ordering people's perceptions about alternative future environments in which today's decisions might play out. They are carefully constructed stories about the future. Each scenario represents a distinct, plausible, internally consistent and challenging future world (van der Heijden, 2006). It must be recognised, however, that scenarios do not aim to make predictions. The future remains unpredictable as ever. Rather, their value lies in helping decision makers understand the complex forces shaping the future. The purpose of scenario development is not to identify the most likely future, but to (Fahey and Randall, 1998): see what possible futures might look like, how they might come about, and why this might happen; produce new decisions by forcing fresh considerations to surface; reframe existing decisions by providing a new context within which they are taken; and, identify contingent decisions by exploring what an organisation might do if certain circumstances arise.

Decisions that have been pre-tested and future proofed in this way against a range of prospects that fate may hold are more likely to stand the test of time. de Geus (1988) argues that decision makers who embrace this process gain the ultimate competitive advantage, while van der Heijden (2006) suggests the process generates a distinctive kind of knowledge and promotes organisational learning. Strategic scenario planning can provide guidance for those involved in conceiving, designing, funding, constructing, occupying and managing the workplace in the following ways:

- Communication: the process acts as a catalyst for initiating dialogue and debate about the future. It can promote communication between the IT, FM 
and HR departments. Also, it fosters active participation in strategic thinking which leads to strategic decision-making.

- Collaboration of Stakeholders: the process is trans-disciplinary. Sometimes, intra company research and decision-making can be subjective and biased with a narrow focus. This process, however, enables organisations to draw on other disciplines (such as, architecture, facilities management, social psychology) and encourage cross pollination of knowledge, expertise and ideas in workplace provision.

- Competition: research has shown that there is a strong correlation between scenario planning and improved financial performance of the organisation (Chermack, 2003).

- Conceptual: the process challenges participant's current assumptions about the future and preconceived ideas about the workplace. The process promotes divergent thinking and encourages managers to think outside the box in order to address issues of common concern that may be overlooked by taking the short-term view.

Scenario development is emerging as a powerful planning tool which provides an effective framework to produce better policy decisions today for the benefit of the future. This paper, therefore, offers a scenario based methodology for understanding the whole range of possibilities that present themselves in the field of workplace provision - Prospective Through Scenarios.

\section{Prospective through scenarios}

The Futures Academy in Dublin Institute of Technology (DIT) has developed a combined methodology for exploring and shaping the future which draws upon the Anglo-American technique of 'scenario planning' and the French futures method of 'La Prospective',. The 'Prospective through Scenarios' process involves the creation of a single preferred future vision known as the 'prospective'. It is created following an in-depth study and the development of ideas and thoughts provoked by a set of scenarios. It is a very formalised, inclusive, comprehensive and rigorous process.

\section{PART TWO}

\section{The 'Workplace of the Future' study}

Johnson Controls Global WorkPlace Solutions and The Futures Academy collaborated on a research project, entitled 'Workplace of the Future', with a view to re-examine how workplace decision-makers anticipate and prepare for future change,

\footnotetext{
${ }^{3}$ The prospective refers to a "much wider approach and activity than other futures methodologies as it comprises not only of the study of the future, and an evaluation of alternative outcomes against given policy decisions, but also the will to influence the future and to shape it according to society's wishes" through the development of a preferred future vision (Ratcliffe, 2008:221).
} 
uncertainty and complexity ${ }^{4}$. Using the prospective through scenarios process, the main objectives are described as follows.

- To redefine the current role and position of their global, sustainable and smart workplace solutions by adopting a holistic futures approach.

- To identify drivers, issues and trends that will have long-term implications for the development of smart and sustainable workplaces.

- To develop a set of possible and preferable future scenarios.

- To create a single preferred future vision of the workplace.

The study consists of three phases of research, which are all centred on three futures workshops. Each phase corresponds to the following themes respectively: global, sustainable and smart future workplaces. In the context of this paper, the outcomes are not examined. Rather, the main focus is on how the methodology evolved and adapted to achieve the noted objectives in order to foster long-term thinking in the field of workplace provision.

\section{An evolving methodology}

This section describes three 'Prospective through Scenarios' methodological frameworks employed during each phase - global, sustainable, and smart- of the workplace of the future study. A description of each is presented, which consists of:

- a step-by-step theoretical account of each methodological framework;

- an explanation of how the process evolved and adapted during the course of the study; and,

- a brief illustration of some of the outcomes generated in this research;

As mentioned before, each phase is centred on three futures workshops. The workshops, however, are only one part of the process. Before and after each one, other futures methods were employed to generate additional data to feed into each one of the workshop products (futures research reports). This paper, therefore, outlines each futures method utilised during the course of the study.

\section{First phase of research: the global workplace}

The specific aim of the first workshop was to explore the global challenges faced by those in the field of workplace provision over the coming two decades. Figure 1 illustrates the main steps of the 'prospective through scenarios' process employed during this phase. The process involves a number of interactive and creative stages that combine the use of various futures methods and techniques.

\footnotetext{
${ }^{4}$ This research was presented as a case study to demonstrate how a generic prospective through scenarios approach could be utilised in workplace provision (Saurin et al, 2008). This paper, however, outlines and critically evaluates three adaptive methodological frameworks employed in the study.
} 


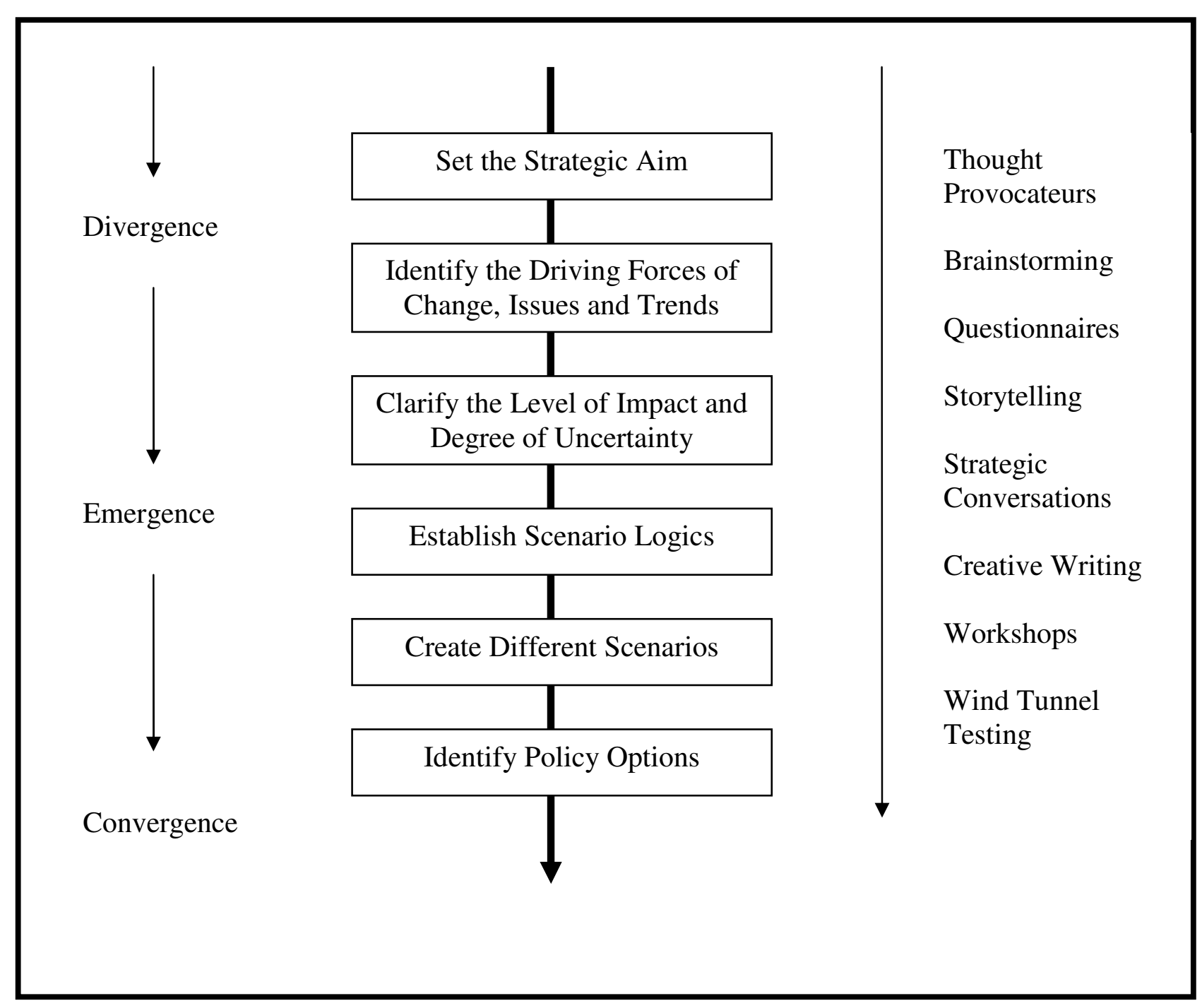

Figure 1: Prospective Through Scenarios Process: Phase One

\section{Set the strategic question}

Setting the strategic question helps to identify the underlying purpose of the work being carried out. The strategic question must be clearly identified, as it will have important implications for the workshop outcomes; a well-defined, well-researched and specific strategic question will produce the best results (Lindgren and Bandhold, 2003). Following a series of interviews and an in-depth documentary review, the strategic question was set as:

How can the Facilities Management community prepare for the future of the workplace considering the following driving forces?

- Knowledge Capital

- Workplace Culture

- Technology and the environment

- Quality of Life

- Large Scale governance 


\section{Identify the driving forces of change, issues and trends}

The exploration of the future starts with the identification of a broad ranging set of driving forces of change. These are the forces, issues and trends in the external environment driving or steering change in one way or another. They are usually categorised by a technique like the 'Six Sector Approach' (Society, Demography, Economy, Environment, Governance, Technology). Ultimately, it is the driving forces of change, issues and trends that shape and propel the story lines described in the scenarios (Schwartz and Ogilvy, 1998).

In this phase, the driving forces of change, issues and trends were explored using a number of techniques, such as, documentary review, brainstorming workshops, strategic interviews, and future-specific questionnaires. During the workshop, the facilitator asked the participants to determine the main driving forces of change, issues and trends at three different spatial levels, namely: meta (global), macro (regional) and micro(workplace).

\section{Identify pivotal uncertainties and establish scenario logics}

The next stage of the process involves identifying the 'pivotal uncertainties'. These are the issues that are most likely to play a critical role in the future; they are characterised by their potentially high level of impact on the strategic question. The participants identified the pivotal uncertainties that have the highest impact on the strategic question and the highest level of uncertainty over the potential outcome (Ratcliffe and Sirr, 2003). Although they have been identified as the most uncertain issues, they indicate a potentially high level of risk for the future that needs to be examined. Pivotal uncertainties are then used to build the scenario logics.

Scenario logics are the basic building blocks from which the final scenarios will eventually evolve. The logical rationale and structure for the scenarios are established at this stage. The logics provide the themes for the scenario's plot. During this workshop, the participants clustered the pivotal uncertainties identified earlier and selected two key uncertainties that they thought might play prominent roles in the future. The uncertainties identified were:

- Economy: High Economic Growth versus Low Economic Growth

- Success in the Workplace: Collaboration versus Competition.

Subsequently, the facilitator polarised and articulated them into a scenario matrix, the $2 \times 2$ matrix approach (See figure 2) in accordance with the work of Schwartz and Ogilvy, 1998; Ringland, 2002; van der Heijden, 2006. Three divergent scenarios emerged in each quadrant of the cross. 


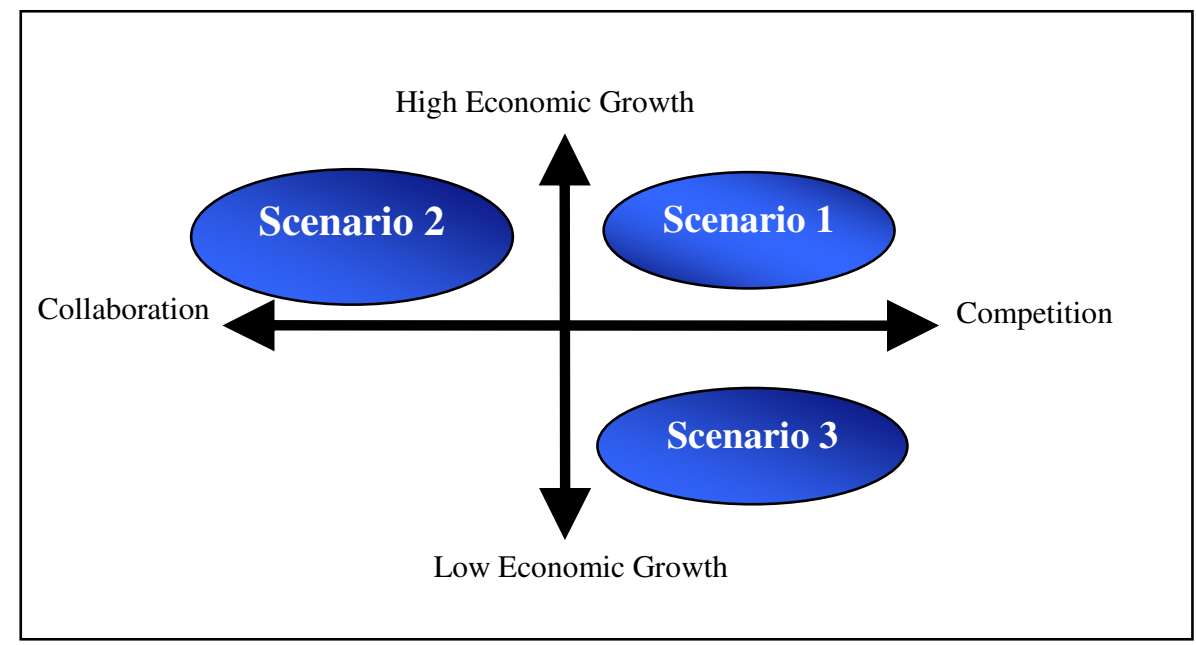

Figure 2: Scenario Logics Framework

\section{Create different scenarios}

Having established the framework structure for the scenarios, the next stage is to flesh out the scenario plots in order to produce useful, coherent and creative narratives about the future. The scenarios should be evocative, provocative and innovative; have a beginning, a middle, and an end; an approximate time-line; key events that make them happen; early indicators of change and an exciting title (Lindgren and Banhold, 2003).

The workshop participants generated the outline for each of the scenarios in a scenario brainstorming session. Following the workshop, however, the project team elaborated the narratives further. The scenarios developed at this stage are outlined as follows:

Jazz - A Global Market by 2030: the workplace is a network.

This scenario assumes an unprecedented acceleration of economic growth, relentless pressure for short-term gains and fierce competition on a global scale, driven by rapid technological advances and further market integration. It is a world where entrepreneurship, innovation and individual responsibility are favoured. Give and take is keenly attuned to the opportunities of the moment and at the same time alert to ways of incorporating long term values into strategies for commercial success. Free market reforms have moved governments everywhere to downsize, deregulate and privatise.

Wise Counsels - A Secure World by 2030: the workplace is a community This scenario assumes global economic stability and an effort to attain environmental balance and social progress. Institutional improvements worldwide facilitate sustainable development. It is a world where collective, collaborative and consensual action is favoured. Decision making has become increasingly delegated and expert. Knowledge has become the key resource. Physical property is no longer the most important asset. Rather, the emphasis is placed on intellectual property. It is the hearts and minds of people that are essential to growth and prosperity. 
Scenario Dantesque - A Fragmented World by 2030: the workplace is a fortress This scenario assumes global economic stagnation, cultural difference and insecurity. Emphasis on distrust, retrenchment and reaction leads to widespread social unrest, conflict and environmental degradation. Instability is widespread across the globe as regions become increasingly disjointed from each other. Racism is rife. The attitude that dominates this world is based on the phrase 'each to their own'.

\section{Identify policy options}

A fundamental part of the process is identifying a set of robust core strategies that are capable of withstanding a wide variety of alternative possible futures (Gannon and Ratcliffe, 2005). This stage involves two important steps:

i. agreeing approximately five broad policy 'themes' or headings; and,

ii. identifying a range of specific action agendas under each of these headings.

Following a brief group discussion, the workshop participants agreed that the five headings in the strategic question represented the most important policy themes, supported by a number of action agendas (See table 2). The identification of these actions can assist decision-makers in workplace provision to understand and anticipate impending change in uncertain and complex market conditions.

\section{Policy Themes and Action Agendas}

Knowledge Capital

- Creating a knowledge management platform will systematically encourage sharing of knowledge between the facilities management, real estate sectors and other departments of an organisation.

\section{Workplace Culture}

- Incorporating employee well being into business plans, strategies and activities will promote health and safety among staff and the supply chain.

\section{Technology and the Environment}

- Identifying technological solutions, like 'smart' workspaces, that are likely to impact positively on the environment, will increase the possibility of working away from the traditional high-energy consuming office space.

\section{Quality of Life}

- Designing the workplace to maximise communication, collaboration, interaction and creativity to encourage a shift from hard work to 'hard fun' as well as providing a social nucleus, as well as a job.

\section{Large Scale Governance}

- Balancing legislation with best practice will help the move towards an improve workplace.

Table 1. Examples of policy themes and action agendas developed in workplace one.

\section{Second phase of study: the sustainable workplace}

The need to develop a sustainable workplace strategy emerged as an important research priority during the first phase of research from which the next workshop brief emerged. The specific aim of the second workshop, therefore, was to explore the 
future workplace, looking specifically at sustainability and corporate social responsibility in the field of workplace provision.

During this research phase, the primary researcher refined the methodology by adapting certain stages of the 'Prospective Through Scenarios' process to ensure the process remained energetic and responsive to the needs of the client. The changes made to the methodological framework in phase two are outlined as follows:

- thought provocateur or experts provoked thought at the outset of the workshop;

- an alternative futures method was used to categorise the drivers, issues and trends - Causal Layered Analysis;

- three more scenarios were produced, but they were nested within the global scenarios produced in the previous workshop;

- ten challenging questions facing workplace managers were identified and answered.

Figure 3 illustrates the main steps involved in the development of sustainable workplace scenarios.

\section{Set the Strategic Question}

Following an in-depth analysis of the first report and a series of interviews, the strategic question was set as:

What might be the future sustainable workplace look like in 2030?

\section{The thought provocateur session}

At the outset of the workshop, a small number of experts in the field of workplace service provision and facilities management were asked to provide a short reflection to provoke thought at the outset of the workshop. They give their personal view of what the sustainable workplace might look like 10, 15, 20 years ahead, and highlighted a number of significant actions that might be done now by the facilities management community to influence that change in a preferred direction. 


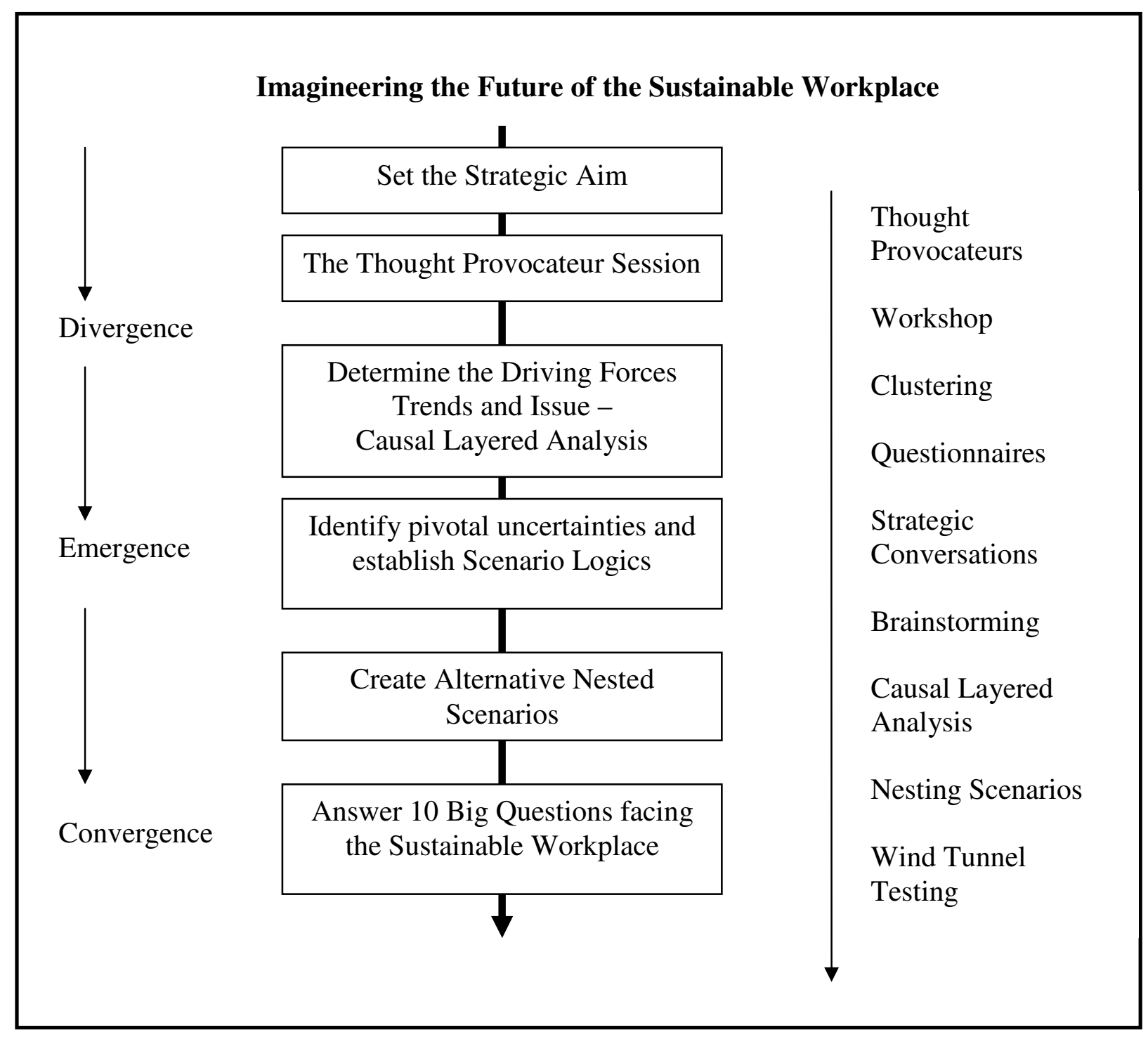

Figure3: Prospective Through Scenarios Phase Two

\section{Using causal layered analysis, determine the driving forces, issue and trends}

Participants were asked to consider forces, trends and issues that would have an impact on the long-term vision of a sustainable workplace and raise the issues of common concern that are often over-looked in the conventional short term view. The framework presented to them to achieve this goal was a causal layered analysis (CLA) futures approach, adapted by the Futures Academy.

CLA is a futures method that guides participants in examining the future through multiple levels of understanding. Participants not only use language and data to define the trends and issues shaping the future, but are also encouraged to focus on deeper levels of beliefs, social causes, metaphors and worldviews (Inayatullah, 2004) This causal layered analysis consists of three layers:

1) Empirical (obvious events, trends and issues);

2) Interpretative (underlying forces and reasons using DEGEST perspectives); and 
3) Exploratory: (analysis of worldviews, cultures and values.

The objective of the CLA method is to conduct research that moves up and down these layers of analysis in order to form alternative futures. Some of its benefits are that it (ibid):

- broadens the range and richness of scenarios;

- shifts the debate beyond the superficial and obvious to the deeper and obscure; and

- guides policy action that is informed by different and deeper layers of analysis.

The participants categorised the forces, issues and trends under three layers as follows:

\begin{tabular}{|c|c|c|c|}
\hline & Empirical & Interpretative & Exploratory \\
\hline Demography & $\begin{array}{l}\text { Encourage } \\
\text { knowledge } \\
\text { interactions } \\
\text { between diverse } \\
\text { generations }\end{array}$ & $\begin{array}{l}\text { Demographic challenges } \\
\text { producing significant } \\
\text { economic pressures such as } \\
\text { income inequality }\end{array}$ & $\begin{array}{l}\text { Fear of individualism and } \\
\text { difference }\end{array}$ \\
\hline Economy & $\begin{array}{l}\text { There is a } \\
\text { challenge between } \\
\text { cost of } \\
\text { sustainability and } \\
\text { payback }\end{array}$ & $\begin{array}{l}\text { Emergence of China and } \\
\text { India onto the global } \\
\text { marketplace becoming } \\
\text { massive consumer markets }\end{array}$ & $\begin{array}{l}\text { Alternative worldview is } \\
\text { ecological economics } \\
\text { which focuses on the } \\
\text { 'dynamic and spatial } \\
\text { interdependence between } \\
\text { human economies and } \\
\text { natural eco-systems }\end{array}$ \\
\hline Governance & Inertia to change & $\begin{array}{l}\text { Increase in the } \\
\text { representation of } \\
\text { traditionally under- } \\
\text { represented groups in trade } \\
\text { union membership }\end{array}$ & $\begin{array}{l}\text { The threat of widespread } \\
\text { theocracies through } \\
\text { widespread } \\
\text { fundamentalist thinking } \\
\text { will be ever present }\end{array}$ \\
\hline Environment & $\begin{array}{l}\text { Unsustainable } \\
\text { transport systems }\end{array}$ & $\begin{array}{l}\text { Increased cost and } \\
\text { decreasing availability of } \\
\text { urban space is leading to } \\
\text { more high rise buildings }\end{array}$ & $\begin{array}{l}\text { What is the accepted } \\
\text { truth about the } \\
\text { environmental status of } \\
\text { our planet? }\end{array}$ \\
\hline Society & $\begin{array}{l}\text { Time for equality at } \\
\text { work }\end{array}$ & $\begin{array}{l}\text { Increased emphasis on } \\
\text { quality of life, there is a } \\
\text { shift away from } \\
\text { materialism and an } \\
\text { awakening of spirituality }\end{array}$ & $\begin{array}{l}\text { Purpose of work - why } \\
\text { did people go to work } \\
\text { and what are we going } \\
\text { for now? }\end{array}$ \\
\hline Technology & $\begin{array}{l}\text { Introduction of } \\
\text { energy efficient } \\
\text { technology in a } \\
\text { complex system }\end{array}$ & $\begin{array}{l}\text { Newly advanced } \\
\text { holograpghic technology is } \\
\text { being developed that will } \\
\text { power a new generation of } \\
\text { pocket sized digital video } \\
\text { projectors }\end{array}$ & $\begin{array}{l}\text { Technology is an enabler } \\
\text { and educator }\end{array}$ \\
\hline
\end{tabular}

Table 2: Examples of drivers, issues and trends identified in the second stage 


\section{Identify pivotal uncertainties and establish scenario logics}

The participants of this workshop identified two important pivotal uncertainties, and they were both polarised to portray the different or opposite ways that each might turn out. In doing this, two alternative future directions were produced, namely:

- Work/Life Balance: The Individual versus The Corporation

- Economy: High Economic Growth versus Low Economic Growth

\section{Create alternative nested scenarios}

The output of phase two was the development of three nested divergent scenarios. A nesting scenario amounts to using the framework of a previously formed scenario and creating a more focused scenario within that general framework. In this instance, three sustainable workplace scenarios were created in the global scenario frameworks presented in phase one.

\section{Hive (within Jazz)}

This scenario assumes a fast paced competitive economy characterised by deregulation and privatisation. The corporate office no longer exists as major disasters cause knowledge workers to take refuge in home-working. The new workplace structure is the 'hive', where employees work in spaces called 'bubbles' that integrate home, work and social life. 'Smart' thinking, design and development become particularly relevant to the technology sector as the demand for customised accommodation and facilities increase.

\section{Eco-office (within Wise Counsels)}

This scenario assumes a stable knowledge based, global economy based on collaboration and consensus, and focused on environmental balance social progress. Eco-offices emerge that are similar to hotels which provide good services to improve the work/life balance and attract the top talent. The emergence of virtual business environments creates a shift towards a decentralisation of many organisations.

\section{Gattaca (within Dantesque)}

This scenario assumes a fragmented, disjointed and insecure world in which economic stagnation emphasises cultural and racial differences. The corporate hierarchical structure is now more prominent and the workplace is similar to a production line in a manufacturing plant. The corporate society has emerged as an all-fearing entity. It controls its employees, by using technology such as finger printing, retinal and genetic identification to control access and information.

\section{Identify ten major questions affecting the development of the sustainable workplace}

By way of a round table discussion, the facilitator initiated a dialogue between workshop participants to encourage the identification of the ten most pertinent questions that face workplace planners and facilities managers with regard to the development and maintenance of the sustainable workplace over the next decade and beyond. 


\section{Third phase of research - the smart workplace}

The need to explore the impact of technology on the future workplace emerged as an important research priority in both the first and second research phases from which the final workshop brief emerged. The objective of the third and final workshop was to explore the impact technology will have on the future development of the workplace.

The primary methodological focus of this phase is based on the final step of the 'prospective through scenarios' process - produce the prospective, as it was not used in the latter workshops. A preferred vision is created based on the notion that the future can be influenced and shaped according to society's wishes. To create the prospective, the researcher has adjusted the process again, and Figure 4 illustrates the main steps employed during this phase. The changes made to the framework in phase three are highlighted as follows.

- A thought provocateur (expert) was assigned to one of five groups to guide discussions during the brainstorming sessions.

- Challenges, issues and trendes were categorised using a different approach called STEEP (Social, Technology, Economic, Environment and Political).

- Participants created one preferred future vision of the Smart Workplace.

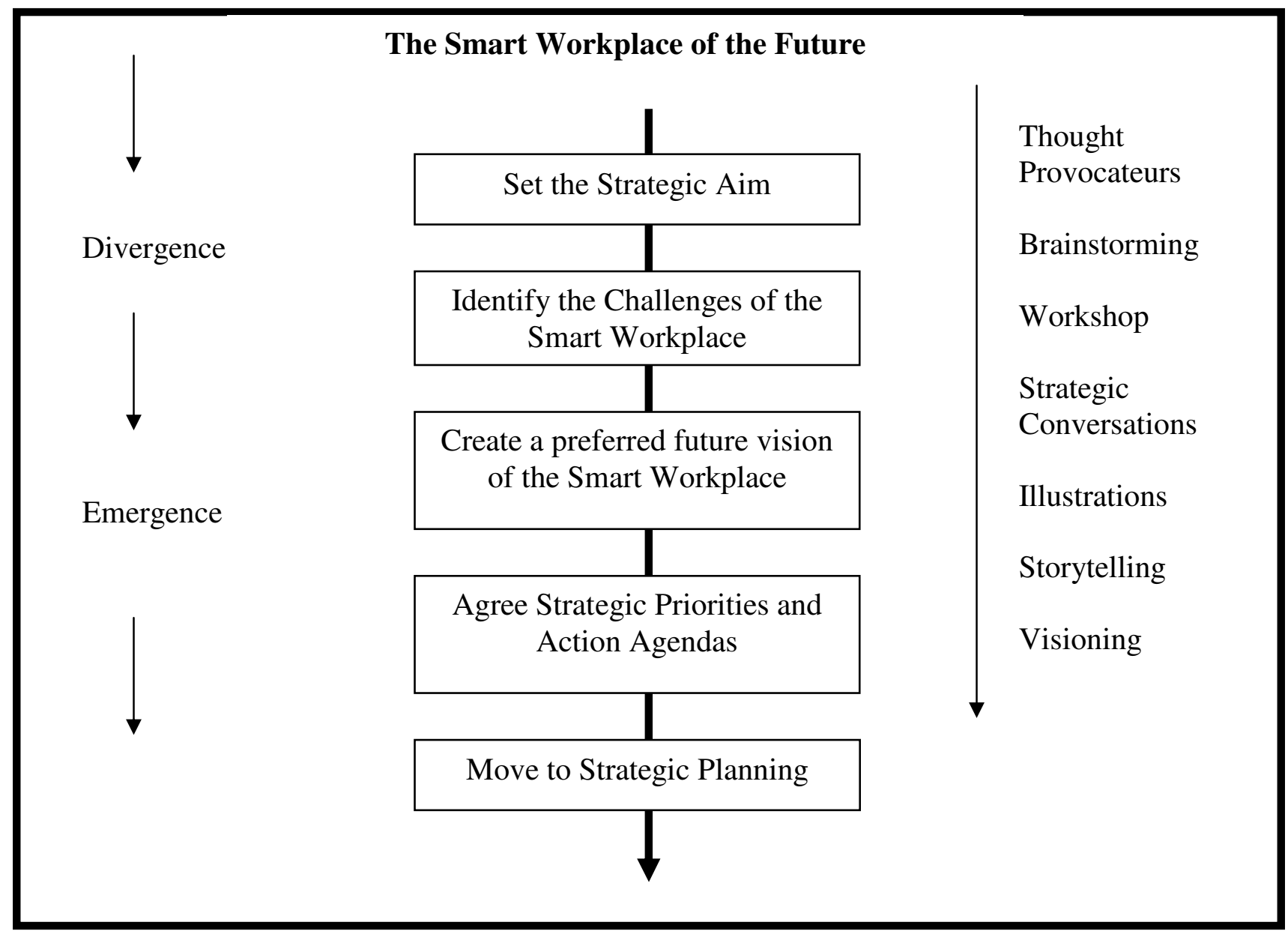




\section{Set the strategic aim}

In the third and final stage of research, the main aim of this project is to explore a preferred future vision of the Smart Workplace, while considering the following questions:

$>$ How will our world of work be transformed through technologies?

$>$ What would be the impact of future technologies on the shape and form of our workplace?

$>$ How will they effect employee's productivity and creativity?

$>$ How should property occupiers and owners, managers and service providers respond to these changes?

\section{Identify the Challenges of the Smart Workplace.}

The facilitator divided the workshop participants divided into five groups, and assigned one thought provocateur (experts) to each group for the day. They identified challenges, opportunities, threats and factors that will affect the future development of the Smart Workplace. To help structure their discussions, the STEEP - Social, Technology, Economic Environmental, Political (van der Heijden et al, 2002) approach was employed.

\section{Produce the Prospective}

Producing the prospective is the crux of this workshop process. It considers the patterns and inter-relationships that emerge between the challenges and opportunities in session one, as well as the possible future conditions, from which a preferred future vision can emerge. The vision must consider a number of factors in order for it to be robust, creative, and most importantly, thought provoking (Bezold et al, 2009):

- It should represent best dreams, hopes, desires, and aspirations.

- It must be plausible but bold enough to enable people to go beyond what they think are there personal limits.

- Must be achievable in the specified timeframe.

During this visioning exercise, each group was asked to imagine themselves in the 'smart' workplace of 2030, and examine it from the following perspectives:

- shape, form and location;

- the way people will work;

- how will people communicate and collaborate;

- what technology will be used; and,

- what will be the implications on cities, the urban landscape, real estate, facilities management and people.

A vision emerged, entitled a 'Day in the Life of a Smart Worker in 2030'. It assumes that technological achievements have reshaped the role of the corporate office to become an enabler of smart effective work characterised by rich communication and collaboration functions. 


\section{A day in the life...}

Nina arrives at her business park where her club office is located. The business park is a mixed blend of corporately owned and public spaces. While walking to her customisable space of choice, her voice controlled mobile device starts the range of on-demand integrated FM\&IT services she requires based on her personal profile. When she arrives at her workspace, she arranges her documents with a flick of the finger, and studies a few key graphs that have arrived together with a video message.

\section{Agree Strategic Priorities and Action Agendas}

Like workshop one, participants identified five broad strategic priorities, each supported by several action agendas, aimed at assisting facilities managers and workplace service providers to move towards the preferred future smart workplace that has been created.

\section{Move to Strategic Planning}

The process of envisioning the future workplace can be outlined in three main stages: strategic thinking, strategic planning, and strategic implementation. The overall study focuses on the strategic thinking phase. The 'prospective through scenarios' process creates a bridge or a kind of 'scaffolding' between strategic thinking and strategic planning across which ideas and action can continue to pass. The process contributes to strategic planning and management by (van der Heijden et al, 2002):

$>$ Creating wide awareness of the imperative requiring change;

$>$ Guiding the formation of operational plans;

$>$ Enlisting key players who have the power to act; and

$>$ Establishing coherence in management action through development of a shared view.

As an element of strategic thinking, foresight enriches the context within which workplace strategy is planned, developed and executed.

\section{Methods and Techniques}

Futures Workshops - A dominant technique used in the research, the workshops facilitated the collaboration between stakeholders from different disciplines, but involved, in workplace provision and management. Workshops are the most efficient method of collecting an abundance of rich data in a short period of time. Workshops can serve as imaginative brainstorming sessions with the aim of working towards a common goal in a relaxed and friendly environment (Jungk and Mullert, 1987;

Gannon and Ratcliffe, 2005). Workshops can be easily adapted in terms of purpose, and more specifically, use or methodological structure, which has occurred in this research. In this study, the duration of each workshop was one day, with attendance ranging from 25-30 people.

Brainstorming - This technique is the underlying modus operandi of all the techniques employed in the study of futures. It is a structured process for having ideas, and is based upon the notion that imagination is the cornerstone of human 
behaviour. Brainstorming has prospered and developed in many ways, becoming a prime component in foresighting, prospective and scenario planning.

Environmental Scanning - This method consists of a systematic scanning of the external environment for precursors, events, signals of many kinds (the driving forces of change) and interpreting their significance. For the purposes of this project, an analysis of different types of documentary sources of information referring to the past, present and future workplace was undertaken.

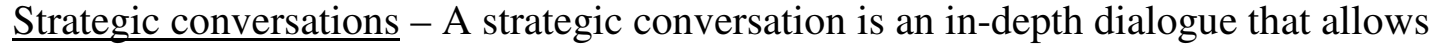
for two-way participation, especially on the part of the interviewer, who takes a more active role than is normally permitted during traditional interview approaches (Ratcliffe, 2002b). In this study, the interviewer conducted strategic conversations with key actors in the field of facilities management and workplace provision to generate qualitative opinion-based data on the areas of strategic importance in the workplace. The interviewees were recognised for their strategic and lateral thinking expertise.

Futures Questionnaires - In this instance, the researcher employed this technique to collect additional primary data about the attitudes, beliefs and opinions concerning the future, and more specifically, the future workplace. The researcher distributed futures questionnaires to people in advance of each workshop to provoke thought before the futures workshops.

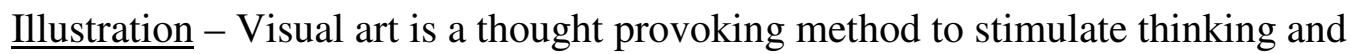
discussion during the workshop. Employed in the third workshop, an artist illustrated the imaginative ideas, thoughts and opinions captured during the workshop session on a mural wall in the workshop. The method boosts confidence to the extent that workshop participants become increasingly engaged in discussion.

Storytelling- It is a fundamental form of human communication. Storytelling, in its most common everyday form, gives a narrative account of an event or an experience. As such, the researcher applied this method to capture the ideas, opinions and views that emerged during the workshop in order to create set of possible and plausible narratives and a preferred future vision of the future workplace.

\section{PART THREE}

\section{Critique of an adaptive methodology}

During the workplace of the future study, the researcher modified the "prospective through scenarios' process for each of the workshops - global, sustainable and smart. A number of underlying reasons are highlighted to explain why this occurred.

Firstly, distinguished by a qualitative line of enquiry, the researcher employed a methodological crystallisation approach to generate robust data and richer data analysis. Crystallisation recognises that there are multiple aspects related to any given problem in the context of the social world. Richardson (2000: 934) uses an analogy of a crystal to describe this approach "which combines symmetry and substance with an infinite variety of shapes, substances, transmutations, multidimensionalities, and 
angles of approach". In this context, the researcher designed an adaptive futures process to employ several futures methods and data sources to broaden the understanding of the research topic and validate findings. The data generated from the three stages of research represent different perceptions, different angles and different approaches to a crystallised problem, the future workplace.

Secondly, the key to managing this research effectively was a flexible research design. During the study, the process became refined and responsive to account for the needs of the client. The researcher introduced new futures methods at each stage of the process to ensure that participants who attended more than one workshop did not tire of the process and exhaust their thinking, but also engaged well with new participants. One of underlying goals of the evolving research design, therefore, was to cater for both 'old' and 'new' workshop participants. The client described how the emergent and adaptive research process injected new energy into each phase of the research.

Finally, the combination of all three phases of research provides a composite picture of the future workplace that is far more comprehensive and robust than any of the stages individually. In the first workshop, the generic 'prospective through scenarios' process was presented. To avoid repetition, there was space to enhance the methodology creatively. As the client gained a greater understanding of the process, more resources became available to use novel and innovative techniques, such as illustration and thought provocateurs, all of which encouraged bigger and bolder thinking from the participants and enhanced their workshop experience. While, these workshops enabled the Futures Academy to re-think, re-evaluate and reflect on the methodology and inspire a more robust and productive process, the emergent research design exposed the participants to new thought processes and techniques - lateral thinking, imaginneering and layered analysis - that opened up their minds to thinking about the future.

To this end, the adaptive and creative methodology now provides a framework to foster long-term thinking in the field of workplace provision and management, by rigorously challenging the mental maps that shape people's perceptions. This methodology, however, does come with its limitations.

\section{Limitations of the Prospective Through Scenarios Methodology}

The real estate (RE) and facilities management (FM) sectors are traditional, and retrospective in nature (Ratcliffe, 2008). Accuracy and quantitative research is the norm in these industries, yet the process employed in this study is subjective and qualitative which is a limitation in itself. In this research, communicating the message of futures thinking was challenging and problematic. When the first report was launched in the RE and FM fields, there was a demand for statistical data to complement the qualitative output of the futures report. Consequently, during the second and third stage of the study, the client conducted a survey amongst its clients to generate statistical data on the sustainable and smart workplace that complemented the qualitative data of the workplace of the future study. This would further suggest that futures studies is being misinterpreted as a predictive science. Whilst there is a clear need for structure, rigour, precision and statistics; there is an overriding need for vision, imagination, creativity and judgement. 
The methodology used in this study is informed by the solid discipline and academic rigour of futures studies. Having been applied in the context of the facilities management (FM) industry, a difficulty arises; maintaining the balance between rigorous intellectual discipline and practice in a sceptical and political FM environment. The FM industry is too pragmatic, operational and reactive. It lacks a broad, forward thinking mindset as this culture is too deeply ingrained. Feedback confirms this; some, not all, members of the FM community have found the output of this study difficult to grasp. In this respect it is not so much the limitation of the methodology, but the limitation of the FM industry. To be competitive in an ever changing environment, transformative strategies are essential for creating a flourishing, sustainable and responsible workplace and built environment.

Although the process was facilitated effectively during the study, some improvements can be made to it. Particular attention should be paid to the following.

- Logistics - during the brainstorming exercises in the first and second workshop, participants were asked to use break out areas off the main room. It was later discovered that the participants did not want to leave the main room as it broke the flow of thinking. Based on this information, the participants in the third workshop were broken into groups at the very start of the day and remained in groups in the common area for the whole day. The benefits of doing this were: no time was lost in separating the groups by sending them to other areas of the building; and, the flow of thinking remained fluid.

- Thought Provocateurs - The link between the thought provocateurs and the group discussions was found to be weak. Feedback suggested the discussions did not reflect what was said at the beginning of the workshop in the thought provocateur session.

- Participant Selection - The participant selection process is critical to the process and must be carefully managed. People attend these events with deep rooted assumptions. Since the process is about thinking outside the box, it is necessary to have people there that are aligned to the client needs in order to generate ideas and think imaginatively.

Despite these limitations, this project has engendered widespread media and industrial interest, not just in the UK, but on an international scale. The response to the Workplace of the Future study output indicates that it has triggered something opened mindsets, prompted debate - to challenge preconceived notions within the industries of real estate and facilities management; it demonstrates that conversation facilitates change.

\section{Conclusion}

The process is often more important than the product itself. Bringing people together to think creatively and share their views, ideas and opinions about a certain problem is frequently as valuable as the particular findings from the effort. This paper has suggested how foresight, more specifically, the 'prospective through scenarios' process, can help explore, explain and enact change in a reactive and technically oriented environment. Additionally, a reflexive and flexible methodology can add 
value to a research project which adds validity, rigour and quality to the overall success of the research project.

\section{References}

Bell, W. (2003) Foundations of Futures Studies History, Purposes and Knowledge. Vol. 1. Transaction Publishers: London

Becker, F. (1999) Beyond Alternative Officing: infrastructure on demand. Journal of Corporate Real Estate. Vol. 1 No. 2 . pp 154 - 168.

Bezold, C., Peck, J., Bettles, C., Olson, B., (2009) Using Vision in Futures. The Millennium Project - Futures Research Methodology V3.0.

Becker. F. and Sims, W. (2000) Managing Uncertainty: Integrated Portfolio Strategies for Dynamic Organisations. Cornell University: New York. Available at: http://iwsp.human.cornell.edu/publications-464.php

Chermack, T., 2003. A methodology for assessing performance-based scenario planning. The journal of Leadership and Organisational Studies, available at: www.highbeam.com/doc/1G1-111769216.html.

Dator, J., (1996) Foreword, In R. Slaughter (ed) The Knowledge Base of Futures Studies. DDM Media Group: Hawthorn, Australia.

de Geus, A., (1988) Planning as Learning. Harvard Business Review. Vol 66. No. 2 pp.70-74

Duffy, F. (2000) Design and facilities management in a time of change. Facilities Journal. Vol: 18, No. 10/11/12, pp371-375.

Duffy, F. and Tanis, J. (1993) A Vision of the New Workplace. Industrial Development Section. Available at: http://dwp.bigplanet.com/pdkconsulting/nssfolder/pdfdownloads1/New_DuffyTanis1993.pdf

Fahey, L., and Randall, R., (1998). Learning from the Future: Competitive foresight scenarios. John Wiley: Toronto.

Gannon, J. and Ratcliffe, J. (2005) Futures Workshops: A Handbook for Practitioners in the Built Environment. The Futures Academy: Dublin.

Gibson, V. (2000) Evaluating Office Space Needs and Choices. Centre for Real Estate Research, Reading University: Reading, UK.

Harris, R. (2006) Real Estate and the Future. In J. Worthington (ed) Reinventing the Workplace. Architectural Press: Oxford. pp50-60

Harrison, A., Wheeler, P. and Whitehead, C. (2004). The Distributed Workplace. Spon Press: Oxon. 
Hayne, B. and Price, I (2004) Quantifying the complex adaptive workplace. Facilities Journal. Vol 22. No.1/2. pp 8-18.

Inayatullah, S., (1998) Pedagogy, Culture and Futures Studies. American Behavioural Scientist. Vol 42. No.3 pp. 386-397.

Inayatullah, S., (2004). The causal layered Analysis Reader. Tamkang University, Taiwan.

Jungk, R., and Mullert, N., (1987). Futures Workshops: How to create desirable futures. Institute for Social Inventions: London.

Kelly, R., Ratcliffe, J. and Gannon, J., 2005. The Global City 2030. The Futures Academy, Dublin. Available at: www.thefuturesacademy.ie

Laing, A. Duffy, F., Jaunzens, D. Willis, S. (1998) New Environments for Working: the re-design of offices and environmental systems for new ways of working. Building Research Establishment: London.

Lindgren, M., and Bandhold, H., (2003) Scenario Planning: The link between the future and strategy. Palgrave MacMillan: Hampshire, UK.

McGregor, W. (1994) An Integrated Workplace. Facilities Journal. Vol12. No.5 pp20-25

McGregor, W (2000) The Future of Workspace Management. Facilities Journal. Vol.12. No.3/4. pp138-143.

Nathan, M. and Doyle, J. (2002) The State of the Office: the politics and geography of working spaces. The Industrial Society: London.

Poli, R., (2010) The many aspects of anticipation. Foresight. Vol. 12. No. 3 pp. 7-17

Price, I., and Akhlaghi, F., 1999. New patterns in facilities management: industry best practice and new organisational theory. Journal of Facilities. Vol 17, No. 5/6, pp 159-166.

Ratcliffe, J. (2002a) Imagineering Cities: creating future 'prospectives' for present planning. Conference paper presented at Turkish Real Estate Seminar III, 2 - 4 May 2002, Istanbul.

Ratcliffe, J.(2002b) Scenario Planning: strategic interviews and conversations. Foresight Journal. Vol 4. No.1 pp19-30 
Ratcliffe, J., 2008. Built environment futures research: the need for foresight and scenario learning. In A. Knight, ed., and L. Ruddock, ed. Advanced Research Methods in the Built Environment. Wiley-Blackwell: Oxford, pp 216-229.

Ratcliffe, J., Saurin, R., Puybaruad, M., and Kristensen, K., (2009) The Smart Workplace in 2030. Johnson Controls Global Workplace Innovation: London.

Ratcliffe, J., Sirr, L. (2003) Futures thinking for the built and human environment: The Prospective Process Through Scenario Thinking for the Built and Human Environment. [Online], [Accessed 14th May 2005]. Available from: http://www.dit.ie/DIT/built/futuresacademy/publications

Richardson, L. (2000) Writing: a method of inquiry. In Denzin, N. K. and Lincoln Y.S. (eds) Handbook of Qualitative Research. (2nd edition) Thousand Oaks: Sage, pp 923-948

Ringland, G (2002) Scenarios in Public Policy, John Wiley, Chicester, UK.

Saurin, R., Ratcliffe, J., Puybaraud, M., (2008). Tomorrow's workplace: a futures approach using prospective through scenarios. Journal of Corporate Real Estate. Vol. 10 No. 4. pp. 243-261.

Schultz, W., (2003). Futures Studies: An overview of basic concepts [Online]. Infinite Futures: Oxford. Available from: www.infinitefutures.com

Schwartz, P. (1991) The Art of the Long View. John Wiley: Chichester, UK

Schwartz, P., and Ogilvy, J., (1998) Plotting your scenarios. Fahey, L. and R. Randal (eds), 1998, Learning from the Future, John Wiley, Toronto.

Slaughter, R., (1996) The knowledge base of futures studies as an evolving process, Futures, Vol 28. No. 9, pp. 799-812.

Smith, S. (2003) Defining Facilities. In R. Best, C. Langston, G. de Valence, (eds). Workplace strategies and Facilities Management. Oxford: Butterworth-Heinemann, pp 11-27

Steelcase (2000) Alternative Officing Strategies. Available at: http://www.oneworkplace.com/pdfs/whitepapers/AlternativeOfficingStrategies.pdf

The Futures Academy (2004). The Futures Academy Compendium. DIT: Dublin. 
van der Heijden, K., Bradfield, R., Burt, G., Cairns, and G., Wright, G. (2002) The Sixth Sense. John Wiley: Chichester, UK.

van der Heijden (2006) Scenarios: The Art of the Strategic Conversation. John Wiley: Chicester, UK

Vischer, J. (2010). Human Capital and the Organisational Environment. In A. BurtonJones, J.C. Spencer (eds) Oxford Handbook of Human Capital. Oxford university press: Oxford. Available at: http://www.gret.umontreal.ca/an/publication.htm

\section{Further reading}

Ratcliffe, J., and Saurin, R., (2007). Workplace Futures: A prospective through scenarios. Johnson Controls Global Workplace Innovation: London.

Ratcliffe, J., and Saurin, R., (2008). Towards Tomorrow's Sustainable Workplace: Imagineering a Sustainable Workplace Future. Johnson Controls Global Workplace Innovation: London.

Ratcliffe, J., Saurin, R., Puybaruad, M., and Kristensen, K., (2009) The Smart

Workplace in 2030. Johnson Controls Global Workplace Innovation: London. 